\title{
A FENOMENOLOGIA DA DIFERENÇA ÔNTICO-ONTOLÓGICA
}

\author{
Michael Marder \\ Investigador do Centro de Filosofia da Universidade de Lisboa \\ Professor de Investigação de Ikerbasque, \\ Departamento de Filosofia, Universidade de País Basco, Vitoria-Gasteiz.
}

Poderá haver mais do que uma fenomenologia? Existem obviamente inúmeras fenomenologias que se referem, se dirigem, e são de alguma coisa, quer seja a perceção ou a experiência religiosa, o mundo social, ou a paisagem e o lugar. Há também algumas fenomenologias associadas mais de perto a certos nomes (por exemplo, Max Scheler ou Maurice Merleau-Ponty), à volta dos quais se agregam movimentos filosóficos e organizações profissionais. Mas o que acontece em abordagens fenomenológicas a determinadas regiões do ente em particular, e na fragmentação da fenomenologia em "escolas de pensamento" está longe de questionar a unicidade e a unidade da fenomenologia; na regionalização, na compartimentação, e na constituição de disciplinas do pensamento fenomenológico, assiste-se simplesmente à sua formalização e a uma divisão institucionalizada do trabalho intelectual. Contra estas correntes perniciosas, Heidegger, em 1927, insiste firmemente numa espécie diferente de multiplicidade dentro da fenomenologia que não seja única: "Não há a fenomenologia única, e se fosse possível haver, nunca viria então a tornar-se algo semelhante a uma técnica filosófica. Pois que na essência de todos os verdadeiros métodos de desvelamento dos objetos verifica-se que aquilo que se dirige a si mesmo é o que fica desvelado através de si mesmo". ' A divisa proto

\footnotetext{
1 Martin Heidegger, Die Grundprobleme der Phänomenologie (Sommersemester, 1927), Gesamtausgabe 24, ed. F.-W. von Herrmann, Frankfurt am Main: Vittorio Klostermann,

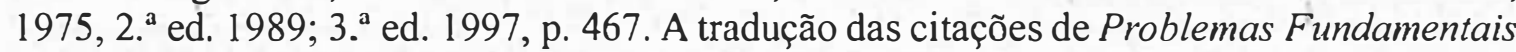
de Fenomenologia é da responsabilidade da tradutora do presente artigo.
} 
metodológica "regressar às coisas mesmas" obriga-nos a retirar indicações e a seguir um caminho a partir dos próprios fenómenos, a partir dos muitos que estão desvelados, sendo que, em cada um dos casos, são eles próprios a dirigir os movimentos de desvelamento. Se não existe coisa alguma que seja "a fenomenologia única", tal fica a dever-se ao facto de não haver um fenómeno passível de ser tomado como exemplo, capaz de prescrever o mesmo método de abordagem para todos os outros fenómenos, de uma vez por todas. Por conseguinte, parece que em questões de fenomenologia, tem de haver mais do que uma.

A dificuldade que se prende com a aceitação incondicional da pluralidade radical reside nos próprios escritos de Heidegger na década iniciada em 1920, em especial, A História do Conceito de Tempo, Ser e Tempo, e Problemas Fundamentais de Fenomenologia. A sua principal preocupação nessa época é a de desvelar os fundamentos ontológicos da fenomenologia, e interpretar efetivamente a fenomenologia como "o método da ontologia". ${ }^{2} \mathrm{~A}$ interpretação ontológica da fenomenologia estende-se das reflexões sobre a intencionalidade enquanto ser de consciência, ${ }^{3}$ até à investigação sobre o modo como o ente das entidades se mostra na autorrepresentação dos fenómenos, ${ }^{4}$ já para não falarmos da tentativa de impor a redução como trabalho de transição do ôntico para o ontológico, de uma apreensão dos entes ao entendimento do seu ser. ${ }^{5}$ Mas o que significa, dentro dos parâmetros da própria filosofia de Heidegger, que a fenomenologia é ou deverá ser levada a cabo como uma ontologia? E não implica o princípio ontológico que a fenomenologia tem de ser posta em prática na diferença entre os entes e o ser, e que portanto, tem de ocupar o espaço, ou melhor, o espaçamento da diferença ôntico-ontológica? Voltando à nossa questão inicial, podemos agora equacionar que, se assim for compreendida, a fenomenologia será uma e mais do que uma, irredutível quer aos entes que se mostram a si mesmos, quer ao ser desses entes que se dá e se retira da autoexibição dos fenómenos.

Já no início dessa década dos anos vinte, Heidegger não estava convicto de que a fenomenologia do seu mestre, Edmund Husserl, contivesse os recursos ontológicos que ele aí procurara. Será talvez este o sentido do reparo contundente deixado por Heidegger numa carta a Karl Löwith, datada de

${ }^{2}$ M. Heidegger, Die Grundprobleme der Phänomenologie, p. 467.

${ }^{3}$ Martin Heidegger, "Hegels Begriff der Erfahrung", in Holzwege (1935-1946), Gesamtausgabe 5, ed. F.-W. von Herrmann, Frankfurt am Main: Vittorio Klostermann, 1977, 2. ${ }^{a}$ ed. 2003, VI, p. 142. Esta e as restantes citações de "O conceito de experiência em Hegel" seguem a tradução de Helder Lourenço, in Caminhos de Floresta, coordenação científica de Irene Borges-Duarte, Lisboa: Fundação Calouste Gulbenkian, 2002, pp. 139-239; aqui, p. 170.

${ }^{4}$ Martin Heidegger, Ser e Tempo, § 36.

${ }_{5}^{5}$ M. Heidegger, Die Grundprobleme der Phänomenologie, pp. 28-29. 
20 de Fevereiro de 1923: "[...] Husserl nunca foi filósofo, nem sequer durante um segundo da sua vida". ${ }^{6}$ Se ser filósofo é pensar ontologicamente, no que diz respeito ao ser dos entes, então, segundo os cálculos de Heidegger, Husserl, que não atingiu o pico do pensamento ontológico, não é filósofo. Conquanto esta avaliação epistolar possa ser injusta, explica cabalmente o motivo pelo qual, no auge do confronto com Husserl, no curso de 1930-1931 na Universidade de Freiburg, Heidegger se inclinou para uma outra fenomenologia - que pode muito bem ser o outro da fenomenologia de Husserl -, a saber, a fenomenologia de Hegel. A minha hipótese de trabalho é dupla e é pois a seguinte: 1) tudo aquilo que Heidegger regista a respeito da fenomenologia do espírito de Hegel (em especial, no que toca à sua posição absolutizadora, absolvente e absolvida) é tido como uma resposta tácita à fenomenologia husserliana ou como a sua refutação; e 2) "Husserl" e "Hegel" são sobretudo para o próprio Heidegger muito mais do que dois nomes próprios associados a duas escolas de pensamento ou duas correntes dentro da, ou simplesmente da, fenomenologia; são em vez disso encriptações daquilo que poderíamos designar, respetivamente, como fenomenologias "ôntica" e "ontológica". Só a impossível e insintetizável posição desprovida de fundamento e situada no meio de ambas, sem mediações entre as duas, conseguirá dar-nos a possibilidade de nos situarmos no espaçamento da diferença ôntico-ontológica específico da fenomenologia, simultaneamente singular e plural, ao mesmo tempo uma e mais do que uma.

Quer sejam implícitas ou explícitas, as respostas e as críticas de Heidegger a Husserl não devem ser tomadas como rejeições totais. São mais rigorosamente o reverso da medalha na censura à filosofia de Hegel in toto, na qual "tudo o que é ôntico no ontológico se dissolve ... sem olhar para o fundamento da possibilidade da própria ontologia", ${ }^{7}$ e por conseguinte, sem salvaguardar a possibilidade - que ainda está viva em Husserl - de reduzir fenomenologicamente o ôntico ao ontológico. Não é suficiente optar ou pela construção reconstrutiva do mundo a partir de posição do saber absoluto, ou pela constituição transcendental do objeto pela consciência pura. Entre as duas fenomenologias, suspensas na "terra de ninguém" da diferença ôntico-ontológica, o pensamento experimentará uma absoluta inquietação, excedendo bem a "inquietação do negativo" dialética, e a negatividade da redução fenomenológica.

${ }^{6}$ Vd. Thomas Sheehan, "General Introduction: Husserl and Heidegger: The Making and Unmaking of a Relationship", in Psychological and Transcendental Phenomenology and the Confrontation with Heidegger (1927-1931). Edmund Husserl's Collected Works, vol. VI, trad., ed., Thomas Sheehan e Richard E. Palmer, Dodrecht/Boston/London: Kluwer, 1997, p. 17.

${ }^{7}$ M. Heidegger, Die Grundprobleme der Phänomenologie, p. 466. 
A tentativa de pensar entre as duas fenomenologias é excecionalmente complicada, em primeira instância devido à férrea insistência de Heidegger no facto de a primeira fenomenologia não ter qualquer relação com a segunda. "A fenomenologia nada tem a ver ... com uma fenomenologia da consciência no sentido atual, i.e., no sentido de Husserl; é necessária uma clara diferenciação [klare Scheidung], no interesse de um real entendimento entre ambas; ainda mais hoje, quando se designa tudo por 'fenomenologia'". ${ }^{8}$ (Acrescentaríamos a necessidade de sublinhar que a negação, em si, deve ser mantida neste ponto sob a mais alta reserva, quanto mais não seja por ser um dos mais potentes mecanismos de defesa do ego identificados pela psicanálise. "Não é a minha mãe", de acordo com o famoso ensaio de Freud sobre a negação, significa exatamente o oposto daquilo que afirma: no sonho, a mulher é a minha mãe, mas seria para mim demasiado traumático confessá-lo. Passa-se o mesmo com a afirmação aqui em causa, designadamente, "Isto não é fenomenologia.") A necessidade de uma "clara diferenciação [Scheidung]" entre as duas não é receita para uma árida comparação académica; nem sequer é uma recomendação metodológica que tenha por objetivo, a todo o custo, fazer avançar o "real entendimento", o que, por si, é uma forma de consciência confinada aos estádios relativamente iniciais da fenomenologia hegeliana. O "real entendimento" de ambas as fenomenologias significa radicalmente outra coisa: o refazer da diferença ôntico-ontológica dentro da e através da "clara diferenciação" que Heidegger acaba de evocar. Esta diferença e esta diferenciação são tão intensas que excluem a possibilidade de uma relação entre as duas fenomenologias, as quais "nada têm a ver" uma com a outra. É de algum modo uma certa não-relação aquela que está em questão, como confirmou Husserl numa nota manuscrita na margem do seu exemplar de O Ser e o Tempo. No único comentário escrito na secção dedicada à conceção do tempo em Hegel, Husserl confessa: "Não consigo aprender nada com isto, mas será que se consegue realmente aprender alguma coisa com isto?"9

Tendo chegado à conclusão de que não tinha nada a aprender com Hegel, a partir do tratamento heideggeriano de Hegel, ou - com toda a probabili-

${ }^{8}$ M. Heidegger, Hegels Phänomenologie des Geistes (Wintersemester, 1930-1931), Gesamtausgabe 32, ed. I. Görland, Frankfurt am Main: Vittorio Klostermann, 1980, 2. ${ }^{a}$ ed. 1988; 3. ${ }^{\mathrm{a}}$ ed. 1997, p. 40.

9 Edmund Husserl, Psychological and Transcendental Phenomenology and the Confrontation with Heidegger (1927-1931); Edmund Husserl's Collected Works, vol. VI, tradução e edição de Thomas Sheehan e de Richard E. Palmer, Dodrecht/Boston/London: Kluwer, 1997, p. 421. 
dade - com os dois filósofos, Husserl desligou o seu pensamento dessa outra fenomenologia, escusando-se e absolvendo-se de algum possível diálogo. Que não há diálogo capaz de articular as duas fenomenologias, aproximando-as, é em parte atribuível ao facto de falarem diferentes linguagens conceptuais, mesmo quando as mesmas palavras (por ex., intenção) se encontram nos respetivos vocabulários. Porém, e ainda com maior importância, tal fica a dever-se à incompatibilidade dos requisitos que cada uma coloca no logos dos phenomena, e também no tornar-se fenómeno do logos, enquanto tal, e no seu todo. Em vez de efetuarem uma cisão dentro do $\log o s$, as duas fenomenologias convocam logoi irreconciliáveis, incapazes de se ouvirem, e ainda menos de se compreenderem ou de aprenderem um com o outro. Não devemos acalentar esperanças numa metalinguagem filosófica capaz de articular ambos os logoi que caem deste lado da dialética do um e do muitos. A inclusão das duas fenomenologias na diferença ôntico-ontológica de Heidegger exclui precisamente uma articulação desse tipo. Tanto quanto a relação entre as duas fenomenologias pode ser concebível, será uma não-relação, ou "uma relação sem relação", na qual pelo menos um dos termos - aquele que é absolutizante ou absoluto - fica absolvido de ligações de racionalidade. Estende-se uma infinitude entre as duas fenomenologias - $\mathrm{a}$ infinitude a ser pensada.

Tal como Heidegger sub-repticiamente a encena, a relação ou a não-relação entre o pensamento de Hegel e de Husserl é uma justaposição da fenomenologia relativa dos entes e da fenomenologia absoluta do ser. Basta um mero olhar sobre esta justaposição para compreender que está longe de se tratar de um simples contraste ou de um alinhamento singelo. Embora Hegel também ofereça aos seus leitores a fenomenologia da consciência "relativa”, esta relatividade, segundo Heidegger, já está reconstruída do ponto de vista do absoluto. A fenomenologia da consciência está compactada na fenomenologia do espírito, desde que se assuma, como Heidegger, que Hegel começa absolutamente pelo absoluto: "[o] outro: ele, o absoluto, é outro, isto é, não absoluto, relativo. O não-absoluto ainda não é absoluto". ${ }^{10} \mathrm{~A}$ consciência cede ao tipo de conhecimento mais relativo, ${ }^{11}$ aquele no qual o absoluto se encontra o mais afastado de si mesmo, e no qual subsiste numa modalidade negativa do "não-absoluto", conquanto ele próprio permaneça. A consciência, se bem que purificada através da redução fenomenológica, é também o horizonte - porventura o horizonte absoluto - da fenomenologia de Husserl. O seu ser é o local onde a relação sem relação de Husserl e de Hegel se vai desdobrar.

${ }^{10}$ M. Heidegger, Hegels Phänomenologie des Geistes, p. 47. Esta e as restantes citações de A Fenomenologia do Espirito são da responsabilidade da tradutora do presente artigo.

${ }^{11}$ M. Heidegger, Hegels Phänomenologie des Geistes, pp. 48-49. 
Antes de considerar as duas ontologias fenomenológicas da consciência, impõe-se aqui uma palavra sobre as tendências absolutizantes da fenomenologia de Husserl. Todas essas tendências se concentram na prática da redução fenomenológica, através da qual Husserl espera alcançar o campo da consciência pura enquanto aquilo que é irredutível, aquilo que sobrevive às operações de elisão, parentesiação e secundarização. O resultado da redução é absoluto, a ponto de ser absolutamente irredutível. A redução é o movimento absolvente de separação do mundo levado a cabo pela atitude natural, de tudo o que é transcendente e dado através de adumbramentos; suspende a consciência natural que, sendo equivalente a uma perspetiva ôntica limitada, "acha sempre e por toda a parte apenas o ente, o que aparece, e julga sobre tudo o que vem ao seu encontro em conformidade com este achamento". ${ }^{12}$

E contudo, as tendências absolutizantes da redução têm falhas e estão truncadas. Assim que se toma partido por um lado, olhando eideticamente apenas na direção da realidade não-adumbrada, a redução husserliana fica aquém do absoluto que não se encontra num dos lados, ou, efetivamente, em nenhum dos lados ("Mas o que é um absoluto que fica de um lado, que absoluto fica de um dos lados em geral? Em caso algum será o absoluto"). ${ }^{13}$ Husserl efetua pouco mais do que uma inversão da atitude natural pela qual a relatividade é idealizada; tendo chegado ao ente não fenomenal, não-adumbrado da consciência, coloca-se ao lado deste ente, olha para o outro lado, ignorando metódica e metodologicamente a relação entre o intencionado enquanto intencionado (noema) e entes simpliciter. Certamente que a parentesiação da realidade adumbrada dispensa o que é dado de modo relativo e incompleto, de uma perspetiva ou de outra, a favor do absoluto dar-se da consciência pura. Mas ao proceder assim, fica do lado daquilo que não tem lados, escapa às dificuldades da mediação, aborta o "diálogo entre o saber natural e o saber real" e a "aferição entre o saber pré-ontológico-ôntico e o saber ontológico", a qual, na leitura de Hegel por Heidegger, constitui a consciência qua consciência. ${ }^{14}$ Onticamente absoluto, o campo da consciência pura é ontologicamente relativo graças à sua própria "pureza", depurado e separado do mundo da atitude natural.

${ }^{12}$ M. Heidegger, "Hegels Begriff der Erfahrung", p. 157, "O conceito de experiência em Hegel”, p. 185.

${ }^{13}$ M. Heidegger, "Hegels Begriff der Erfahrung", p. 134, "O conceito de experiência em Hegel”, p. 161.

${ }^{14}$ M. Heidegger, "Hegels Begriff der Erfahrung", p. 184, "O conceito de experiência em Hegel", pp. 212-213. 
O ser da consciência, descoberto por meio da redução fenomenológica, é a intencionalidade, a direccionalidade da consciência em direção a alguma coisa; o seu ser, em cada caso, de uma coisa. A consciência intencional é conhecimento relativo (e, portanto, ser relativo), par excellence. Por inerência é relacional, gira à volta do que é intencionado, pese embora tenha sido separado da realidade adumbrada enquanto tal. E, neste aspeto, diverge do conhecimento absoluto, o qual já não é ou ainda não é conhecimento de alguma coisa: "Não é o conhecimento, enquanto tal, conhecimento de...? É exatamente o que Hegel nega e tem de negar, quando afirma que se trata de conhecimento qualitativo e não de um conhecimento absoluto relativo". ${ }^{15}$ Ainda antes do seu cumprimento na intuição, onde os atos noéticos e os seus alvos noemáticos ficam juntos em correlações estritas, a intencionalidade é essencialmente um relatum. A orientação ôntica da intencionalidade fica exposta na sua direccionalidade em direção ao que é percecionado, recordado, antecipado, e assim por diante, opondo-se à trajetória do conhecimento absoluto que "não fica preso, mas solto, absolvido daquilo que sabe, e enquanto absolvido - absoluto - poderá também vir ainda a ser conhecimento". ${ }^{16} \mathrm{~A}$ absolução do conhecimento absoluto do conhecido faz explodir correlações noético-noemáticas, libertando-nos finalmente da "teoria da correspondência da verdade", a qual projeta uma longa sombra sobre todo o campo da consciência pura. $O$ verdadeiro não é o cumprimento da vazia intencionalidade na intuição ou na presença ôntica do intencionado; é antes o todo (isto é, ser ou o próprio conhecimento absoluto).

Devemos estar recordados de que neste ponto as queixas de Heidegger contra o conhecimento absoluto puramente ontológico, a que deu voz tão-somente alguns anos antes da sua primeira abordagem consistente a Hegel, incidiam sobre o facto de esse tipo de conhecimento dissolver os entes mesmos e ignorar "esta pertença conjunta e primordial do comportamento perante o ente e do entendimento do ser". ${ }^{17}$ Implicitamente, Heidegger estende o mesmo reparo a Husserl, o qual, por contraste com Hegel, privilegia o comportamento intencional direcionado aos entes sobre o entendimento do ser. Enquanto a fenomenologia relativa se dedica ao aparecimento dos fenómenos dentro de um saber ligado ao conhecido (o nome deste elo é intencionalidade, consciência de...), a fenomenologia absoluta ocupa-se do aparecimento fenomenal do logos. Neste sentido, "[a fenomenologia] é [...] a autorrepresentação absoluta da razão (ratio - $\Lambda$ ó ${ }^{\circ}$ ) , cuja essência e realidade Hegel encontrou no

\footnotetext{
15 M. Heidegger, Hegels Phänomenologie des Geistes, p. 20.

${ }^{16}$ M. Heidegger, Hegels Phänomenologie des Geistes, p. 21.

17 M. Heidegger, Die Grundprobleme der Phänomenologie, p. 466.
} 
espírito absoluto". ${ }^{18}$ Só na diferença entre as duas fenomenologias, em vez de numa síntese de ambas, na qual pelo menos desaparece tanto, quanto aquilo que aparece, vamos vislumbrar "o recíproco pertencer original" do ôntico e do ontológico, dos fenómenos e do logos.

Ora, será que a acusação inicial de que Hegel se entrega a um esquecimento dos entes se faz ouvir, acima de tudo, na própria leitura de Heidegger da Fenomenologia do Espírito? Na construção reconstrutiva do mundo de um ponto de vista do conhecimento absoluto, nós - os que temos conhecimento absoluto - preocupamo-nos com a verdade do ser e com a verdade dos entes, com o próprio conhecimento e com o que é conhecido: "Temos assim no nosso saber dois objetos, ou seja, duas vezes um objeto, e necessariamente por isso ao longo de toda a Fenomenologia, porque para nós o saber é fundamentalmente e sempre, aquilo que em si, e de acordo com a sua essência formal, já tem e já traz consigo o seu objeto outra vez". ${ }^{19}$ Desde que o conhecimento absoluto, visto do ponto de vantagem do absoluto, for ainda mais ou menos outro em relação a si próprio, desde que seja condicionado pelo conhecido, a sua intencionalidade cinde-se, o alvo noemático desdobra-se no saber e no objeto deste saber. A nossa atenção, por sua vez, divide-se entre os dois objetos ou, em alternativa, ganha uma fissura ao esforçar-se na direção de um objeto duplo e espectral ("duas vezes um objeto").

Chamemos desde já a estes dois objetos ou ao duplo objeto, o que se conta duas vezes, pelos seus nomes: o ontológico e o ôntico, o ser dos entes, posto nos termos da autoconsciência, ou num texto tardio de Hegel, "a experiência", ${ }^{20} \mathrm{e}$ o conhecido, entes experimentados à medida que são conhecidos e experimentados. O absoluto é apenas absoluto se abarcar estas duas modalidades, sem ter necessariamente de as reconciliar, isto é, se as mantiver juntas numa tensão que se aproxime da intensidade da diferença ôntico-ontológica. Tocado pelo absoluto, o objeto torna-se excessivo, torna-se mais do que si próprio, transborda os limites da sua identidade, cinde-se em dois e torna-se um e o mesmo duas vezes (as inflexões dialéticas e ontológicas deste "ou" devem ser claramente audíveis). E o ser? Não é, também, mais ou menos do que si próprio, desde que a ele ganhemos acesso através da diferença ôntico-ontológica, na qual tão-somente aparece e da qual se retira (enquanto nada no ser)? À luz desta analogia, o ana-logos, onde o redobrar ( $a n-$ ) abunda, podemos ter em conta a observação que Dominique Janicaud fez de passagem num texto

${ }^{18}$ M. Heidegger, Hegels Phänomenologie des Geistes, p. 42.

19 M. Heidegger, Hegels Phänomenologie des Geistes, p. 68.

${ }^{20}$ M. Heidegger, "Hegels Begriff der Erfahrung", pp. 184-185, "O conceito de experiência em Hegel”, pp. 212-213. 
sobre o diálogo Hegel-Heidegger: "[...] a mais secreta aproximação [de Heidegger] a Hegel [...] encontra-se porventura escondida na fricção respeitante à fenomenologia". ${ }^{21}$

A cisão dialética do objeto do conhecimento no saber e no que nele é conhecido atinge o cerne daquilo que para Hegel constitui o ser da consciência. Em oposição à ontologia da consciência em Husserl, condensada na afirmação "O ser da consciência é a intencionalidade", a definição especulativa de Hegel proclama que "O ser da consciência é a autoconsciência". Aquilo que na fenomenologia de Husserl teria sido o cúmulo da teoricidade empobrecida, de uma reflexão sobre a reflexão que trata os atos noéticos como novos objetos noemáticos, e de um subsequente afastamento extremo do conhecimento das "coisas mesmas", também conhecida pelo nome de crise das ciências, é na dialética de Hegel a figura da riqueza e da concretude que marca o conhecimento absoluto. A orientação ôntica da consciência dirigida ao fenómeno, do ponto de vista desse conhecimento, é inseparável da sua direccionalidade ontológica dirigida a si mesma, num movimento de reflexão que não acontece como um pensamento posterior, já desgarrado da realidade vivida, antes acompanha a construção reconstrutiva da experiência desde o seu começo absoluto. Por conseguinte, saber em absoluto significa "não ficar absorvido no que é conhecido, mas antes transmiti-lo enquanto tal, como aquilo que é conhecido, para onde pertence enquanto aquilo que é conhecido e de onde provém". ${ }^{22}$ Significa, contra Husserl, que a vida da consciência não tem de extinguir-se na presença do intuído e que a intencionalidade vivida, a dunamis do esforçar-se na direção de...., não tem de ser concretizada para alcançar a sua finalidade, (consequentemente, encontrar a morte) nisso em cuja direção se esforça ${ }^{23}$ No cenário no qual a intencionalidade se concretiza, estancando a inquietação constitutiva da consciência, o ser do Dasein reúne-se evidentemente ao ser dos seus alvos intencionais, quando nas operações da consciência "o saber...se esquece de si mesmo e se perdeu somente no objeto". ${ }^{24} \mathrm{O}$ autoesquecimento do saber resulta numa autocompreensão automática do Dasein como algo presente-à-mão, ao passo que o seu ser, que "se perdeu somente no

${ }^{21}$ Dominique Janicaud, "Heidegger-Hegel: An Impossible 'Dialogue'?”, in Endings: Questions of Memory in Hegel and Heidegger, edição de Rebecca Comay e de John McCumber, Evanston, Illinois: Northwestern University Press, p. 41.

22 M. Heidegger, Hegels Phänomenologie des Geistes, p. 66.

${ }^{23}$ Emmanuel Levinas desencadeia uma crítica paralela a Husserl, declarando que "it is a question of descending from the entity illuminated in self-evidence toward the subject that is extinguished rather than announced in it.", in Discovering Existence with Husserl, trad. R. Cohen e M. B. Smith, Evanston, Illinois: Northwestern University Press, 1998, p. 156.

${ }^{24}$ M. Heidegger, Hegels Phänomenologie des Geistes, p. 185. 
objeto", anula a diferença ôntico-ontológica. A absolutez da fenomenologia absoluta implica por outro lado, a possibilidade positiva de ficar perdido no objeto - a possibilidade de a consciência se perder nela mesma enquanto seu próprio objeto e, portanto, a possibilidade de se reencontrar em si mesma.

$*$

Em defesa da fenomenologia de Husserl, a redução demonstrou que a própria consciência não aparece e que, além disso, o ser-consciente da consciência define-se pela sua não-aparência, pelo seu não adumbrado dar-se, o que o separa da realidade transcendente e, por conseguinte, de tudo o que é não-Dasein. É evidente que a ontologia da pura consciência é distinta da consciência que está presente-à-mão. E inversamente, na dialética, "[o] aparecer do saber que aparece no seu aparecer é ela mesma a ciência", ${ }^{25}$ o que não se encontra de todo isolado da realidade adumbrada. Muito depende, todavia, dos modos de objetivação ou de fenomenalização distinguirem as duas fenomenologias. Quando o próprio logos surge no conhecimento relativo, fá-lo enquanto mera alienação ou amortecimento do sujeito, cuja vida psíquica se extingue pela auto-evidência. Mas quando entra em cena e se dá o seu aparecimento fenomenal no campo do absoluto, o logos fica na posse de si mesmo e revigora-se. A consciência da consciência e a intencionalidade da intencionalidade não apresentam vestígios do carácter derivativo e abstrato, que lhes é atribuído na fenomenologia de Husserl; antes reúnem o ser do absoluto, o qual, na sua separação ou absolução absolvente do tudo relativo, é absolutamente inseparável (inalienável) de nós: “o absoluto, em si e para si, está já

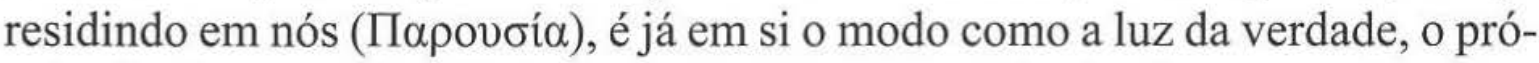
prio absoluto, nos irradia [anstrahlt]. O conhecer do absoluto encontra-se no raio da luz, devolve-o, refrata-o e é assim, na sua essência, o próprio raio, e não apenas um meio, através do qual o raio [Strahl] tivesse sido o seu caminho". ${ }^{26}$

O ser-connosco do absoluto é o seu tornar-se-fenomenal, o tornar-se que é tão supérfluo, quanto necessário, na medida em que acontece depois do absoluto já se ter tornado tudo aquilo que é, exatamente desde o princípio. O brilhar do absoluto sobre nós não nos ilumina do exterior, colocando-se como um objeto por cima e contra nós, mas antes irradia de dentro, como uma luz refletida ou refratada ("devolve-o, refrata-o"), com a luminosidade

${ }^{25}$ M. Heidegger, "Hegels Begriff der Erfahrung", p. 143, "O conceito de experiência em Hegel”, p. 171.

${ }^{26}$ M. Heidegger, "Hegels Begriff der Erfahrung", pp. 130-131, "O conceito de experiência em Hegel”, p. 157. 
ontológica da consciência enquanto autoconsciência, e por fim, como espírito absoluto. (Não podemos deixar de mencionar, entre parênteses, que ser-com o absoluto merece uma paciente análise desconstrutiva. Se o absoluto é um absoluto connosco, perde então a sua identidade enquanto absoluto, e já não é um, é antes mais do que um, separado minimamente de nós, tanto quanto de si mesmo como unidade simples, pela proximidade - a absoluta proximidade da sua presença. A separação do absoluto de si mesmo nada mais é do que a expressão da diferença ôntico-ontológica alegadamente esquecida na fenomenologia de Hegel).

Ora o raio intencional do ego transcendental na fenomenologia de Husserl emite uma luz subjetiva que brilha sobre os objetos intencionais e que é absorvida nas superfícies noemáticas intencionais que atinge. Quando está connosco, o raio já está fora de nós, orquestrando a auto-transcendência da consciência enquanto consciência de.... A sua trajetória é unidirecional: a consciência intenta uma outra coisa, embora não uma outra em absoluto (isto é, não o transcendente) e é alienada de si própria quando os atos noéticos de perceber, recordar, etc., se tornam objetos noemáticos da sua intencionalidade. Mas o absoluto, nos termos de Heidegger, "tenciona ser connosco" e por conseguinte intenciona-nos, sempre que nós próprios intentamos seja o que for, numa inversão da direccionalidade intencional, característica de toda a onto-teologia. A perda desta outra intencionalidade empobrece drasticamente a ideia fenomenológica de constituição. Seria claramente um exagero grosseiro vir defender que a subjetividade constitutiva de Husserl é puramente ativa, visto que, dentro da produção hilomórfica de sentido, retira o seu sentido específico daquilo que constitui. Mas ao passo que na fenomenologia relativa da consciência, o constituinte é, até certo ponto, constituído onticamente pelo constituído, na fenomenologia absoluta do espírito, o constituinte é ontologicamente constituído pelo absoluto que tenciona. Em grande parte do seu pensamento, Heidegger irá trabalhar sobre a inversão da intencionalidade, detetável na dialética de Hegel, e imbuída de conotações ontológicas. O “apelo do ser" em Ser e Tempo e, em sentido diverso, na "Carta sobre o Humanismo", bem como o apelo do pensar que gira em torno da questão "O que é pensar?" são apenas dois dos exemplos proeminentes desta inversão ontológica. ${ }^{27}$

A reversibilidade ontológica da intencionalidade é a razão pela qual, numa rara crítica explícita à "fenomenologia atual”, posta em contraste com a fenomenologia do espírito, Heidegger escreve: “[...] é decisivo que na expressão

${ }^{27}$ Vd. Martin Heidegger, "Carta sobre o Humanismo," edição consultada: Basic Writings. Ed. David Farrell Krell, New York: Harper Collins, 1993, p. 245. Veja-se igualmente "what is called thinking-and what does call for it?" in Martin Heidegger, What is Called Thinking?, trad. J. Glenn Gray, New York \& Cambridge: Harper \& Row, 1968, p. 21. 
'fenomenologia do espírito' o genitivo esteja determinado com rigor. Não se trata de um genitivus objectivus, cujo significado é hoje em dia especialmente fácil de tomar como se se tratasse de uma investigação fenomenológica sobre o espírito, como estabelecendo a diferença para com uma fenomenologia da natureza ou da economia". ${ }^{28} \mathrm{O}$ espírito não é (ou pelo menos, não é exclusivamente) o objeto da fenomenologia, mas é também o seu sujeito; "a fenomenologia é [...] a maneira e o modo como o próprio espírito é. A fenomenologia é o verdadeiro e completo sair do espírito". ${ }^{29}$ Por outras palavras, não há equivalência semântica entre duas expressões aparentemente paralelas - "a fenomenologia da consciência" e "a fenomenologia do espírito" -, a não ser que se entenda a primeira como um modo de aparecimento da segunda. Na fenomenologia da consciência contemporânea, o logos esbate-se no "estudo" dos fenómenos, mesmo quando e se, em especial, procura o seu método a partir das coisas mesmas. Esta fenomenologia não é da consciência, no sentido de um genitivo subjetivo, porque a própria consciência não aparece, e não lhe é permitido aparecer nela; a fenomenologia não é a maneira pela qual a própria consciência existe. É tanto assim que, extrapolando a partir das conclusões de Heidegger, a consciência, tida como objeto de estudo fenomenológico, cessa de existir, perde as suas determinações existenciais, e deixa de se distinguir dos domínios da natureza ou da economia. A finíssima linha de demarcação, que atravessa o genitivo em fenomenologia de..., está nada menos encarregada de manter a diferença ôntico-ontológica, deitada por terra no pensamento de Husserl. Há certamente mais do que uma fenomenologia, e também não menos pelo facto de o genitivo em fenomenologia de... ser necessariamente equívoco.

A objetivação transcendental da consciência na fenomenologia husserliana, como fenomenologia $d a$ consciência mas não uma fenomenologia própria da consciência, dá forma aos conceitos de experiência e verdade. A verdade ôntica de experiência é a veracidade do está presente-à-mão, o cumprimento e a confirmação da vazia intencionalidade na intuição das coisas mesmas. ${ }^{30} \mathrm{~A}$ função mais crucial da consciência é a de verificar a apropriação do que é adequado e a solidez da relação entre o experimentante e o experimentado. Quer isto dizer que a sua função gira quase inteiramente em torno de julgar a precisão e de medir os graus de proximidade entre o que é "meramente" intencionado e o que é "realmente" intuído, no tipo de juízo pré-predicativo ou não-predicativo, inerente aos atos de perceção, e de consolidar todos os assim

${ }^{28}$ M. Heidegger, Hegels Phänomenologie des Geistes, p. 33.

${ }^{29}$ Ibid., p. 34.

${ }^{30}$ Ibid., pp. 28-29. 
chamados juízos abstratos. ${ }^{31}$ A experiência, para Husserl, é juízo, e, ao passo que a consciência sente a inquietação ôntica de alternar entre os dois pólos de comparação, ela vê-se privada da inquietação ontológica que se experimenta quando se vagueia sem tomar abrigo na cisão entre o ôntico e o ontológico, no espaçamento da diferença ôntico-ontológica. Qualquer inquietude residual é sujeita a uma pacificação imediata através de uma aplicação mais exigente dos atos de comparar, pesar, e julgar. O que está portanto ausente da fenomenologia relativa da consciência é a experiência da experiência a qual nada tem em comum com a consciência teorética, o ser da experiência que "significa ser esta diferenciação" ("entre o verdadeiro ôntico e a verdade ontológica"). ${ }^{32}$ E o que se perde em qualquer correlação estabelecida pela consciência, por maior que seja a precisão com que se julga o mútuo-pertencer dos seus dois elementos, é a verdade ôntico-ontológica absoluta da experiência.

Quando nas décadas de 1930 e de 1940 Heidegger explora os textos de Hegel, está em busca desta mesma verdade, que está tão ostensivamente em falta na fenomenologia husserliana. A verdade como verdade do absoluto, se não mesmo a verdade absoluta, é experiência na significação ontológico-existencial do termo: "A vontade do absoluto de estar junto de nós, quer dizer, de aparecer para nós como o que parece, vigora como experiência". ${ }^{33} \mathrm{Na}$ verdade, a vontade do absoluto, que quer "ser connosco", os conhecedores do absoluto, cumpre o reverso da intencionalidade que já aqui invoquei, de tal modo que não somos apenas os sujeitos experimentantes, mas também os objetos experimentados dessa vontade. (Posteriormente, Levinas irá traduzir esta tomada do sujeito como alvo, por parte do absoluto, pela perseguição ética do eu pelo outro). Desta perspetiva sem dimensão do absoluto, a experiência ôntica dos fenómenos dados, efetivamente do dar-se fenomenológico interpretado como dádiva de si, do absoluto, apresenta-se sob uma nova luz. A experiência não é, no julgar, uma desapaixonada comparação e avaliação do que se adequa entre a intencionalidade e a intuição; é antes o pathos de passar por..., o ser-transformado da consciência com o experimentado, consigo próprio, e com o absoluto: "a palavra 'experiência' no significado de adquirir experiência com alguma coisa [mit etwas seine Erfahrung machen]". ${ }^{34} \mathrm{O}$ "com" da experiência

${ }^{31}$ Edmund Husserl, Experience and Judgment: Investigations in a Genealogy of Logic, trad. James S. Churchill e Karl Ameriks, Evanston, Illinois: Northwestern University Press, 1973, p. 64.

${ }^{32}$ M. Heidegger, "Hegels Begriff der Erfahrung", p. 177, "O conceito de experiência em Hegel", p. 206-207.

${ }^{33}$ M. Heidegger, "Hegels Begriff der Erfahrung", p. 191, "O conceito de experiência em Hegel”, p. 221.

${ }^{34}$ M. Heidegger, Hegels Phänomenologie des Geistes, p. 30. 
acomoda as mais subtis inflexões da existencialidade, tais como o ser-com, Mitdasein, da consciência se reporta à facticidade do seu desdobrar-se junto dos objetos, ao regresso reflexivo a si mesma como autoconsciência, e ao seu ser em absoluta proximidade (Пароvбía) do absoluto. Esta pequena preposição "com" congrega, sem que os sintetize, o positivo e o negativo, o ôntico e o ontológico, o existencial e o categorial de modo a que, ao fazê-lo, a diferença ôntico-ontológica possa ocupar o seu não-lugar. Apenas o primeiro dos três significados de "experiência com" ressoa ainda na fenomenologia da consciência relativa, a qual, não obstante, dilui a rica existencialidade do "com" na adequação que foi julgada e na compertença do experimentante e do experimentado, através da qual a intencionalidade é cumprida e extinta.

A experiência com... é o sofrimento com..., é ser mutuamente transfigurado por aquilo com que nos deparamos na experiência ou no sofrimento. A verdade do absoluto e a absolutez do absoluto não excluem, antes necessitam, talvez paradoxalmente, de alteração dialética. A verificação especulativa, em alternância entre a consciência experimentante e o conteúdo experimentado, verifica e autentica a verdade de ambos no seu tornar-se, e através desse tornar-se uma outra coisa que não aquilo que são: do lado do experimentante, "[a consciência] confirma a verdade do que realmente é", de modo a que "[n]essa confirmação da verdade perde a sua verdade inicial, o que primeiro e antes do mais pensava de si mesma", ${ }^{35} \mathrm{e}$, do lado do experimentado, "esse algo é confirmado na sua verdade...como não sendo o que quase parece ser, antes sendo na verdade outro [sondern in Wahrheit anders] ". ${ }^{36}$ A verificação não só precisa de tempo para ser cumprida - como também tem em conta o tempo. Em última instância, a experiência com... e o sofrimento com... condensam em sofrimento a perda da autoidentidade inicial da consciência que tem vindo a ser mudada juntamente com essa de que era consciente, algo que permanece impensável na determinação clássica dos atos noéticos ("o intencional dirigido a" que ou atinge ou falha o seu alvo). Nos termos de Husserl, esta perda terá sido explicada como referência a um lapso de juízo, incluindo um lapso na própria experiência que não conseguiu trazer o experimentado firmemente para dentro do seu alcance. Tal fica a dever-se ao facto de a ideia fenomenológica de tempo, na medida em que pertence às correlações noético-noemáticas, significar apenas um deferimento temporário da presença da coisa à intuição, o vazio provisório da intencionalidade que ainda não foi ou que já foi cumprido. Fundamentalmente, nada muda, quer no que intenciona, quer no intencionado, 
uma vez que a direccionalidade-para da consciência é realizada nesse "para" no qual foi orientada desde o início.

Bastante diferente é agora a verdade dialética da experiência que germina na alteração da consciência e no seu duplo objeto. O início é absoluto, porém, neste início, o absoluto, mantendo-se ou caindo o mais longe possível de si próprio, é outro em relação a si próprio, enquanto a sua alteridade se traduz na relatividade da consciência. Para que se toque na verdade do absoluto, a verificação tem de transmitir esta alteridade verdadeiramente como outra, in Wahrheit anders, sem que dessa forma negue a verdade do início e sem repetir o erro dos juízos ônticos que descartam o erróneo que há no "sendo o que quase parece ser". Embora Heidegger acuse Hegel de contribuir para a dissolução do tempo - "a filosofia hegeliana formula através do desaparecimento, entre outras coisas, do tempo, a filosofia da ciência, isto é, o saber absoluto" 37 - e faça alinhar esta contribuição metafísica com a insistência de Husserl na cientificidade da fenomenologia, ${ }^{38}$ o carácter temporal da verdade na fenomenologia do absoluto contesta estas conclusões do curso de 1930-31. Em traços gerais, a crítica que Heidegger lança contra a temporalidade hegeliana ${ }^{39}$ é bem conhecida: o tempo da dialética ultrapassa e cobre a temporalidade estático-existencial do Dasein, em especial quando ocorre a "queda" mediada do espírito no tempo. E contudo, a tese que considera a verdade como uma alteração, pela qual passam tanto o experimentante, como o experimentado, torna difícil argumentar que o tempo ficou excluído do pensamento hegeliano do ser. Se "experiência" for o nome para "o ser dos entes", 40 então a essência do ser dos entes é o tempo, o tempo da experiência e a experiência do tempo. O crucial na experiência é a passagem do ôntico e do ontológico exatamente por entre a fenomenologia do espírito.

Uma reconstrução próxima e muitas vezes simpatética do pensamento de Hegel, nos textos de Heidegger e nas lições dos seminários das décadas de 1930 e de $1940,{ }^{41}$ deixa-nos contudo diante da conclusão de que as duas feno-

${ }^{37}$ Ibid., pp. 17-18.

${ }^{38}$ Ibid., pp. 15-16.

39 M. Heidegger, Being and Time, $\S 82 \mathrm{~b}$.

${ }^{40}$ M. Heidegger, "Hegels Begriff der Erfahrung", p. 180, "O conceito de experiência em Hegel”, p. 208.

${ }^{41}$ Vd. igualmente os textos sobre a negatividade, de 1938-1939 e de 1940-1941, reunidos no volume 68 da Heidegger Gesamtausgabe, bem como partes de Ser e Tempo, os cursos sobre 
menologias não são adequadas no que diz respeito às questões interligadas dos entes e do ser. A fenomenologia do espírito faz com que os fenómenos se dissipem no logos; a fenomenologia da consciência faz com que o logos se dissolva nos fenómenos. Hegel é apontado como tendo traído a questão dos entes, die Frage nach dem Seienden, por desencadear a Aufhebung, ${ }^{42}$ para não falar da Aufhebung dos próprios entes no ser. Husserl é acusado indiretamente de negligenciar a questão do ser, elidida ou posta de lado no decurso da redução fenomenológica que liberta a consciência pura de tudo o que é transcendente, ao mesmo tempo que relativiza onticamente o ser da consciência. A fenomenologia como empreendimento ontológico (ou seja, ôntico-ontológico) - no papel que Heidegger lhe reservou em Ser e Tempo - não tem lugar no exclusivo privilegiar dos fenómenos ou do logos, tanto mais ainda porque não é e não pode constituir-se como tal em nenhuma das duas variedades. Quando se faz do logos o absoluto, "[n]ão há nenhuma [introdução] porque não pode haver nenhuma introdução à fenomenologia"; ${ }^{43}$ quando se dá prioridade aos fenómenos, nada mais há a não ser uma introdução à fenomenologia, uma "conceção preliminar" ou Vorbegriff. No meio da suspensão entre as duas (mas haverá apenas duas?), no espaço ou no espaçamento entre a ausência da introdução e a introdução insistente, entre o logos e os fenómenos, entre o um e os outros, temos de começar, não podemos começar, queremos começar.

Tradução de Elisabete M. de Sousa

\section{ABSTRACT}

This paper focuses on Martin Heidegger's reading of the Hegelian phenomenology of spirit as a veiled critique of Edmund Husserl's phenomenology of consciousness. Ultimately, I argue, Heidegger will acknowledge the insufficiency of either phenomenology, concerned exclusively with Being or with beings, and will hint at the possibility of a third kind of phenomenology unfolding between the two - the phenomenology of ontico-ontological difference.

a Lógica de Hegel e sobre a Lógica de Aristóteles e de Hegel, e ainda os escritos sobre a Filosofia do Direito de Hegel, recentemente publicados no volume 86 da Gesamtausgabe.

${ }^{42}$ M. Heidegger, Hegels Phänomenologie des Geistes, p. 60.

${ }^{43}$ M. Heidegger, "Hegels Begriff der Erfahrung", p. 205, "O conceito de experiência em Hegel”, p. 236. 